\title{
CONOCIMIENTO HISTÓRICO Y PATRIMONIALIZACIÓN DE UN ENCLAVE DE LA MONTAÑA CANTÁBRICA: LAS UBIÑAS
}

\author{
David Gallinar ${ }^{1}$, Cristina García-Hernández ${ }^{2}$ y Jesús Ruiz-Fernández ${ }^{3}$ \\ Universidad de Oviedo
}

\begin{abstract}
RESUMEN
Las Ubiñas, como tantos otros espacios montañosos de la Península Ibérica, ha pasado de constituir un medio marginal y de difícil acceso en el que, aun así, se desarrollaban actividades humanas de cierta relevancia socioeconómica, a ver consagrada su patrimonialización a través de su encaje en las diferentes figuras de protección previstas a tal efecto por la legislación española e internacional. Este proceso, que culmina con la reciente declaración de este espacio como Parque Natural y Reserva de la Biosfera, vino precedido por un proceso de reconocimiento y divulgación, el cual, hasta hoy, no había sido explorado. Este estudio, basado en la recopilación y análisis de documentos históricos y bibliografía especializada, examina la información contenida en diversas fuentes exponiendo los principales testimonios cartográficos y artísticos que aluden al Macizo de las Ubiñas, así como los recogidos en memorias de viajes y de investigación que tuvieron como escenario este espacio, que, a pesar de su privilegiada ubicación central en el Macizo Asturiano, fue ignorado por los protagonistas de las grandes exploraciones científicas y hazañas deportivas de principios de siglo $\mathrm{XX}$, y experimentó un reconocimiento relativamente tardío de sus innegables valores naturales y paisajísticos.
\end{abstract}

Palabras clave: Fuentes históricas; Montañas Cantábricas; paisaje natural; patrimonialización; Peña Ubiña.

\section{HISTORICAL KNOWLEDGE AND PATRIMONIALIZATION OF AN ENCLAVE OF THE CANTABRIAN MOUNTAINS: LAS UBIÑAS}

\section{ABSTRACT}

The Ubiñas Massif, as so many other mountain areas of the Iberian Peninsula, went from being a marginal environment in which, even so, human activities of a certain relevance were developed, to see its heritage consecrated through the different protection figures provided by the Spanish and international legislation. This process of patrimonialization, which culminates with the declaration of this space as a Natural Park and Biosphere Reserve, was preceded by a process of recognition and dissemination. This study, based on the compilation of historical documents and bibliography, examines the information contained in different sources, exposing the main cartographic and artistic testimonies alluding to the Ubiñas Massif, as well as those collected in travel memories and research reports conducted in this space, which, despite its privileged location in the Asturian Massif, was ignored by the great scientific explorations and sports exploits of the early 20th century, and experienced a relatively late recognition of its undeniable natural values and landscapes.

Key words: Cantabrian Mountains; historical sources; natural landscape; patrimonialization; Peña Ubiña.

\footnotetext{
${ }^{1}$ Departamento de Geografía de la Universidad de Oviedo davidgallinar@hotmail.com

${ }^{2}$ Departamento de Geografía de la Universidad de Oviedo cristingar@hotmail.com

${ }^{3}$ Departamento de Geografía de la Universidad de Oviedo ruizjesus@uniovi.es
} 


\section{INTRODUCCIÓN Y ÁREA DE ESTUDIO}

Nuestra percepción hacia los espacios de montaña ha ido variando a lo largo del tiempo, pasando de constituir un medio en el que se desarrollaban ciertas actividades humanas (y con el que, por tanto, solamente nos unía un lazo material) a ser identificados con valores simbólicos (mágico-religiosos, científico-humanistas) y, finalmente, a convertirse en un espacio para la acción social a distintos niveles, con relevancia desde el punto de vista político y económico (MOSCOSO-SÁNCHEZ, 2004). De hecho, muchos de estos sectores, los cuales ocupan un lugar destacado en el proceso de valoración moderna del paisaje (ORTEGA CANTERO, 2018), han acabado por consagrar su patrimonialización a través de su encaje en las diferentes figuras de protección que, con tal fin, fueron surgiendo (Parques Nacionales, Parques Naturales, Reservas de la Biosfera, Lugares de Interés Geológico, Paisajes Protegidos, etc.), siendo este el caso del espacio que nos ocupa.

Las Montañas Cantábricas tienen en el Macizo de las Ubiñas (figura 1) uno de sus principales conjuntos altimontanos, sólo comparable en altitud a otros como Picos de Europa o al Macizo de Fuentes Carrionas, por constituir los tres únicos sectores en este ámbito con cumbres que superan los 2.200 m s.n.m. Las Ubiñas están enclavadas en el Macizo Asturiano, en su sector central, donde sobresalen netamente entre los relieves montañosos de su entorno por su elevación y su vigorosidad, al contener 58 picos que superan los 2.000 metros s.n.m., entre los que destacan las cumbres de El Fontán Sur (2.417 m s.n.m.), El Fontán Norte (2.416 m s.n.m.) y Penubina "La Grande" (2.414 m s.n.m.), entre otras (figura 2).

Respecto a la extensión y delimitación del área de estudio, esta cuenta con una superficie de 12.000 hectáreas, lindando al noroeste con el entorno de Los Garrafes, al nordeste con las proximidades de Llindes, al sudeste con el Altu'l Palo y al sudoeste con las inmediaciones de Turrebarriu. Desde el punto de vista administrativo, la crestería de las Ubiñas supone la divisoria entre las Comunidades Autónomas del Principado de Asturias y de Castilla y León (provincia de León), extendiéndose el área estudiada por los municipios asturianos de Teberga, Quirós y Ḷlena, y por el de Santu Mitsanu, en León. Las condiciones climáticas de este ámbito son las características de la alta montaña cantábrica, con temperaturas medias anuales de $\sim 6^{\circ} \mathrm{C}$ a la altitud de El Meicín, una precipitación anual de entre 1.100 y 1.400 mm en función de la orientación, así como una importante innivación.

Tenemos evidencias de la ocupación temprana de este espacio; durante la campaña espeleológica realizada en 2012 en una sima localizada en la Paré los Cinllos (próxima a los Fontanes) se encontraron los restos de un varón de entre 16 y 18 años de edad, los cuales fueron datados en 2014 por $\mathrm{C}^{14}$ en $3.850 \pm 50$ años de antigüedad, por lo que se trataría del primer vestigio de ocupación humana del que se tiene constancia dentro de este espacio montañoso (Interclub Ubiña del Colectivo Asturiano de Espeleólogos). Además, en los concejos asturianos de Lḷena, Quirós y Teberga, así como en el babiano de Santu Mitsanu, que abarcan la totalidad del Macizo de las Ubiñas, se conservan restos castreños, túmulos y dólmenes neolíticos, siendo ejemplares los de La Cobertoria (Quirós-Ḷlena), que dan testimonio de un poblamiento primitivo en el perímetro del área de estudio. A esto hay que añadir el descubrimiento de una punta de palmela, industria propia del Calcolítico, aunque, al no tenerse constancia de la existencia en el sector de un grupo con entidad propia durante este período, parece más conveniente atribuirla al comprendido entre el Neolítico Final y el Bronce Antiguo, en torno al 2000 antes de nuestra era (GONZÁLEZ ÁLVAREZ, 2016). Este tipo de hallazgos han sido relacionados con la ocupación del área por parte de grupos pastoriles que frecuentaban este espacio en época estival, aprovechando los pastizales de altura, en lo que sería una primitiva trashumancia desde tierras castellanas (BLAS CORTINA, 2011; ONTAÑÓN PEREDO, 2003; GONZÁLEZ ÁLVAREZ, 2016).

En cuanto a los modos y formas de vida, es destacable el impacto y la importancia que la trashumancia de las ovejas merinas ha supuesto para las Ubiñas desde, al menos, la Edad Media hasta finales del siglo XX (1988), ya que ha dejado su impronta en el paisaje, la toponimia y la economía local. Así pues, aún quedan vestigios de los numerosos "corros" que tuvieron utilidad hasta hace pocos años, además de pasos para el ganado. Algunos topónimos refrendan esta actividad, como es el caso del "Camín de las Merinas", el "Chozu las Merinas" y "Las Merinas" 
(LUEJE, 1958). Otras actividades que tuvieron cierto desarrollo fueron las manufacturas con fines comerciales y de autoconsumo, lo que permitió cierta conexión entre la vertiente asturiana, que exportaba principalmente madreñas y aperos de labranza, y la leonesa, donde las cosechas eran más prolíficas y abundantes, permitiendo la elaboración de pan y alimentos. En cualquier caso, la situación de los lugareños era precaria y existían dificultades para subsistir, más aún con el recrudecimiento climático que supuso la Pequeña Edad de Hielo (GARCÍA-HERNÁNDEZ et al., 2018).

FIGURA 1

Mapa de localización del Macizo de las Ubiñas

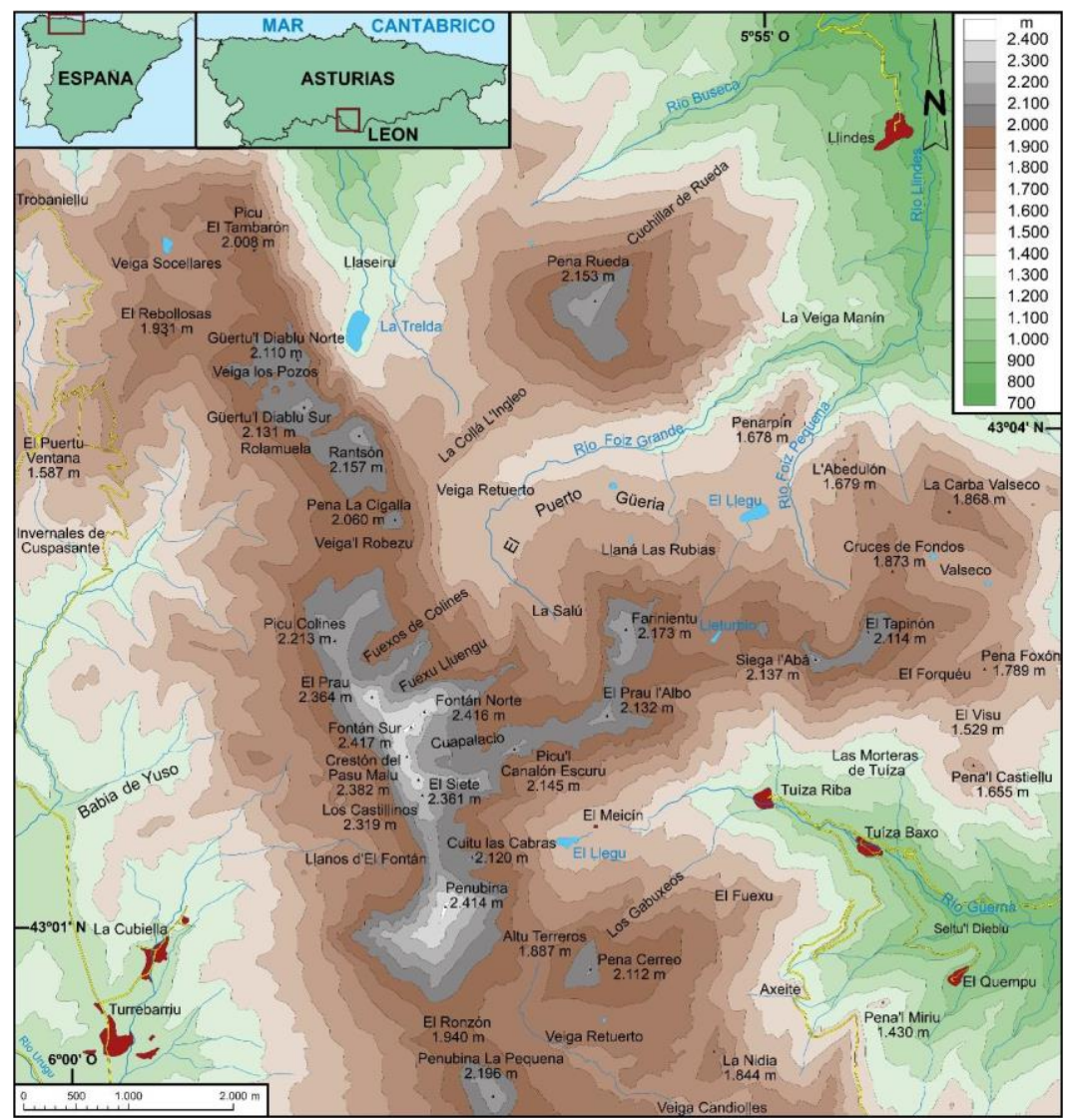

Fuente: elaboración propia.

Parece evidente que es necesario conocer su historia para comprender el verdadero significado actual de este tipo de territorios, muchos de los cuales han pasado por un proceso de valoración y patrimonialización que hoy les sitúa en un escenario de privilegiada protección en comparación con otros espacios naturales. Pero no solamente su historia natural, la más larga, sino la cultural, aquella que, ya en el último suspiro de su dilatada cronología, los vincula al ser humano. Resulta interesante esta reflexión del maestro MARTÍNEZ DE PISÓN (2014) en relación al proceso de patrimonialización de los espacios de montaña en general, y del valle de Ordesa en particular:

Hace poco estuve recorriendo el valle de Ordesa (...) no encontré a nadie que fuera irrespetuoso con la naturaleza o que no mostrase admiración hacia el escenario. Ésa es también la enseñanza de un parque nacional, la conducta en el lugar. Volví, pues, dando las gracias a Ramond, que descubrió literariamente el valle a los ilustrados franceses; a Schrader, que lo honró con sus escritos y dibujos y que lo controló geográficamente con sus mapas; a Briet, que supo divulgarlo con calidad y que tuvo la iniciativa de proponerlo como parque nacional...

En definitiva, tal como afirma Martínez de Pisón (2014), la idea de la protección paisajística y ambiental, que marca el devenir de una parte no desdeñable de la superficie de las montañas 
íbéricas en la actualidad, nace a partir de unos valores naturales, pero se produce en un nivel cultural. Partiendo de esta idea, conocer las principales fuentes históricas (cartografía, imágenes $\mathrm{y}$ documentos de diverso origen) que atestiguan las relaciones establecidas entre el ser humano y dicho medio de montaña a lo largo de la historia, resulta útil para comprender el proceso a partir del cual un espacio de montaña particular es resignificado y, finalmente, puesto en valor desde el punto de vista ambiental, simbólico y, a menudo, identitario. En este sentido, diferentes trabajos han reflexionado sobre el proceso histórico a través del cual se atribuye un valor simbólico al paisaje de las montañas españolas (MARTÍNEZ DE PISÓN, 2004; 2014; GARCÍA-ÁLVAREZ, 2013; ORTEGA CANTERO, 2009; 2012; 2014), y son destacables trabajos que, junto con la caracterización de los principales valores naturales del área estudiada, reconstruyen el modo en que se ha dado la interacción entre el ser humano y el medio, a través de la recopilación de fuentes históricas y bibliografía especializada. Tal es el caso de los trabajos realizados por GONZÁLEZ TRUEBA y SERRANO (2007) en la montaña de Los Picos de Europa, o los de CORNEJO NIETO $(2014 ; 2015 ; 2017)$ en Sierra Nevada. En este último conjunto montañoso, estudios como los de GÓMEZ-ORTIZ et al. (2012; 2018), y el de OLIVA et al. (2014), demuestran que este tipo de información puede llegar, incluso, a resultar útil para complementar la información aportada por otro tipo de registros, realizando reconstrucciones paisajísticas y paleoambientales.

En el conjunto que representa el Macizo de las Ubiñas, pese a su entidad geográfica, su relevancia socio-cultural y pese a contar con innegables valores naturales y paisajísticos (los cuales no han sido ajenos a quienes, a lo largo de los siglos, se han adentrado en él), no existen hasta la fecha aportaciones similares. El presente trabajo pretende llenar el vacío existente con respecto al conocimiento histórico de este espacio montañoso, a través de la consecución de los siguientes objetivos: i) recopilar la información disponible sobre los inicios de la ocupación humana y las primeras referencias históricas sobre este espacio; ii) exponer los principales documentos cartográficos y artísticos que aluden al Macizo de las Ubiñas; iii) recopilar los principales testimonios recogidos en memorias de viajes y de exploración científica que tuvieron como escenario este espacio; iv) analizar el proceso a través del cual Las Ubiñas se han configurado como espacio natural protegido, al que precedió la divulgación de sus valores naturales y paisajísticos.

\section{METODOLOGÍA}

El presente trabajo se ha realizado a partir de la consulta de los documentos, fotografías y cartografía histórica existentes en el Archivo Histórico de Asturias, el Muséu del Pueblu d'Asturies, así como la Biblioteca Nacional de España. Paralelamente se obtuvo información del Sistema de Información Territorial del Principado de Asturias (SITPA), así como de la Biblioteca Virtual del Principado de Asturias. En el caso de las obras pictóricas, fue determinante la consulta de la página web "La mirada de la Montaña", así como la de diversas publicaciones que abordan este tema de forma específica (LUEJE, 1958; MARTÍNEZ y SEVILLA, 2013).

En cuanto a la nomenclatura y la toponimia, este trabajo utilizará la toponimia tradicional en asturiano y su variante dialectal propia del noroccidente leonés, el patsuezu, para lo cual se ha realizado una labor de documentación (ÁLVAREZ, 1949; NEIRA MARTÍNEZ, 1955; CONCEPCIÓN, 1992A; 1992B; 2001; GONZÁLEZ GARCÍA, 2005) y recogida de estos nombres. Es necesario mencionar que, parte de la información contenida en este artículo, se ha recopilado a partir de la realización de un prolongado trabajo de campo que ha involucrado el análisis de otros aspectos relativos al conocimiento geográfico de este espacio y, en particular, a la comprensión de sus características geomorfológicas. De hecho, este estudio se enmarca en el desarrollo de una tesis doctoral centrada en el análisis de las formas de modelado glaciar y periglaciar en la alta montaña de las Ubiñas. A lo largo de dicho trabajo de campo, desarrollado entre los años 2012 y 2019, se han realizado entrevistas a la población local del área, tanto en la vertiente asturiana como en la leonesa. En concreto, 10 de los informantes consultados han sido seleccionados, por su amplio conocimiento del área estudiada, para la realización de entrevistas que incluían preguntas de carácter abierto, especialmente centradas en los usos del suelo actuales y pasados, la toponimia tradicional, y la ubicación de algunos de los elementos que se mencionan a lo largo del estudio. 
Asimismo, se hará referencia al área de estudio como "las Ubiñas". Si bien este término no ha sido empleado hasta fechas recientes, habiendo sido más habitual denominarlo como "Peña Ubiña" o "Cordal de Ubiña" (en castellano), o Penubina, Pinubina o Ubina (en asturiano). En la actualidad "las Ubiñas" constituye un término ampliamente aceptado, que incluso da nombre al Parque Natural de las Ubiñas y la Mesa.

FIGURA 2

Vista del Macizo de las Ubiñas desde la Autopista del Güerna

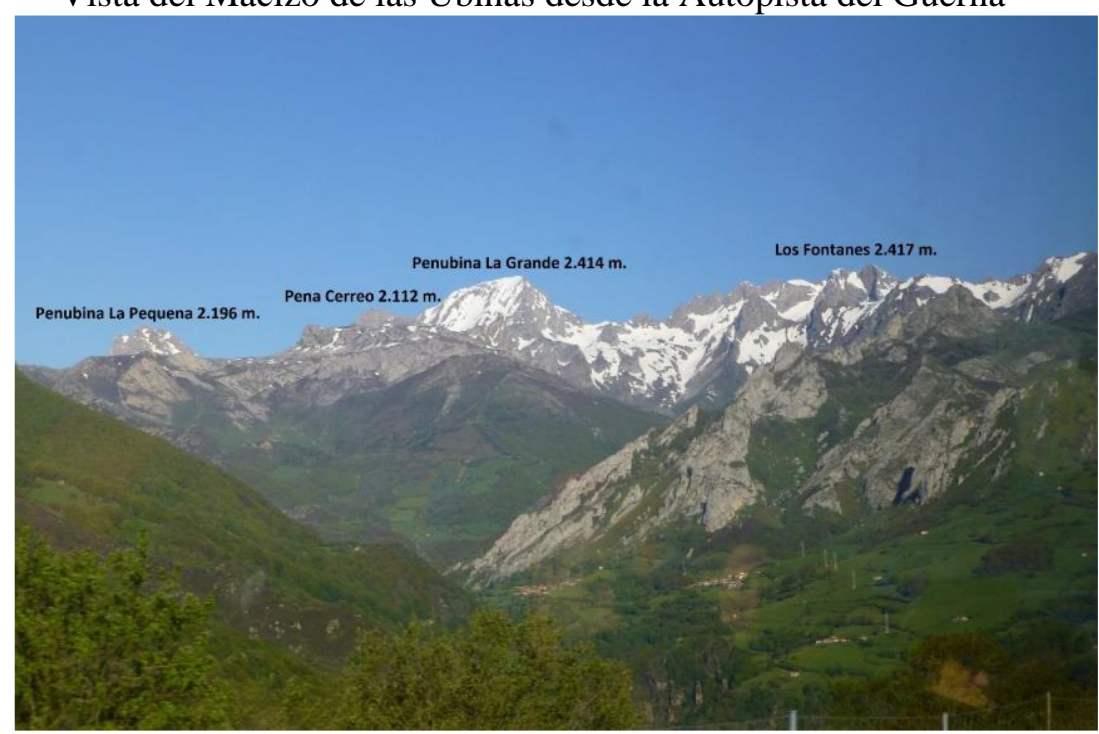

Fuente: realización propia (3 de junio de 2013).

\section{EVOLUCIÓN DEL CONOCIMIENTO SOBRE EL MACIZO DE LAS UBIÑAS}

\subsection{PRIMERAS REFERENCIAS DOCUMENTALES}

A pesar de no haber sido inicialmente un foco de atracción para el montañismo, la investigación, los viajes de aventura o la exploración (a diferencia de otras montañas cercanas como los Picos de Europa, o de referentes europeos como los Pirineos o los Alpes), el Macizo de las Ubiñas cuenta con diversas referencias históricas en forma de documentación histórica, relatos de viajeros y cartografía. Las primeras apuntan hacia el Mons Vindius o Vinnius (Monte Vindio o Vinnio), cuya ubicación y crónicas parecen señalar directamente hacia las Ubiñas, aunque no se descarta la posibilidad de que pudiese haber ocupado un espacio más amplio, o incluso de que se tratase realmente de los Picos de Europa, como así indican algunos autores (GONZÁLEZ TRUEBA y SERRANO, 2007).

No obstante, las Ubiñas, por sus características y localización, parece el conjunto montañoso que mejor concuerda con esta teoría. Así pues, Claudius Ptolemaeus (Ptolomeo, 100-170) orientó el Mons Vindius hacia el Sur de Lucus Asturum, ${ }^{4}$ ubicación que se ajusta con el emplazamiento del Macizo de las Ubiñas. Asimismo, el Mapa de Hispania, recogido en su obra: Geographia o Atlas del Mundo (figura 3), representa el Vindius Mons como una cordillera al Norte de la Península Ibérica, del mismo modo que aparece en la Tabula Peutingeriana ${ }^{5}$, aunque en este caso la figuración de la citada cordillera ocupa una extensión menor, centrándose en un sector que coincide con la situación de las Ubiñas.

Además de estos mapas históricos, legados por cartógrafos del Imperio Romano, han subsistido hasta nuestros días crónicas y relatos de quienes han inmortalizado el Bellum

\footnotetext{
${ }^{4}$ Ptolomeo, II, 6, 20. Biblioteca Nacional de España. Llugo de Llanera, actual población situada a escasos kilómetros al Norte de Uviéu.

${ }^{5}$ Se desconoce la edad de este mapa, la copia más antigua que se conserva actualmente data del siglo XIII.
} 
Cantabricum et Asturicum (Guerras Astur-Cántabras, 29-19 a.n.e.). En este sentido, el historiador romano Lucius Annaeus Florus (Floro, siglos I-II) citó estas montañas en su obra Epitomae Historiae Romanae: "eminentissimum Vindium montem" (altísimo monte Vindio), ${ }^{6}$ llegando a decir que eran tan inaccesibles que los astures, seguros de sí mismos, afirmaban que antes lo ascenderían las olas del mar que las legiones romanas. Por su parte, Paulus Orosius (Orosio, 383?420?), historiador, teólogo y sacerdote romano, escribió en su libro Historiae adversus paganos: "in Vinnium montem natura tutissimum" (muy seguros en la naturaleza del monte Vinnio), ${ }^{7}$ en referencia hacia los astures, comentando que no era posible acceder a estas montañas con la maquinaria pesada de guerra romana, por lo que la táctica que debieron emplear fue la de cercarlos con el fin de hacerles pasar hambre, como así sucedió, ya que durante el otoño del año 25 a.n.e., en el que se personó César Augusto debido a la dificultad de la conquista y la hostilidad de las batallas, la mayoría de estas tribus nativas perecieron por el frío y la inanición: "asediados por el hambre, perecieron casi hasta el último" "perdiendo así territorios y fuerzas militares, aunque el conflicto todavía se prolongó durante otros seis años.

FIGURA 3

Fragmento del Mapa de Hispania de Ptolomeo

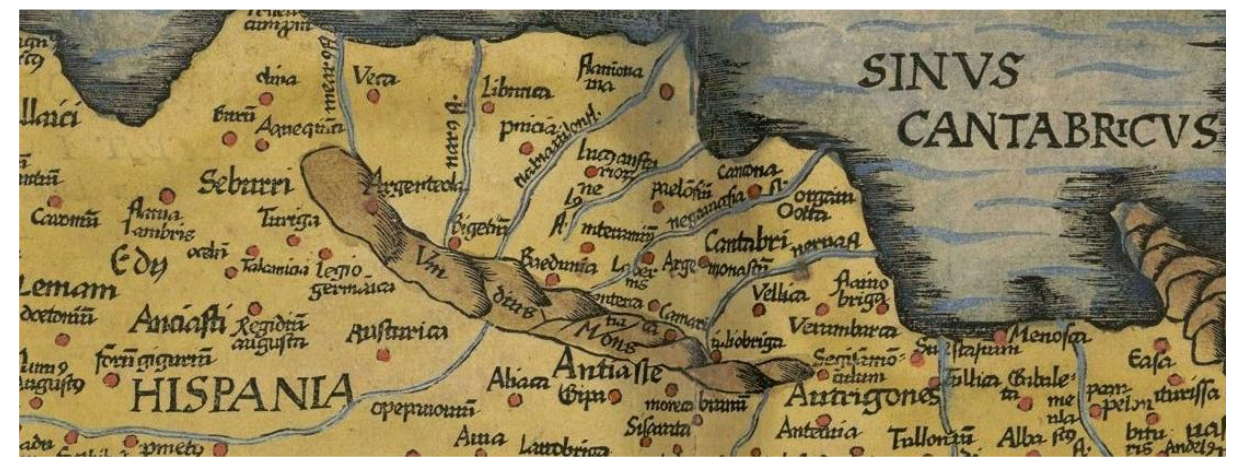

Fuente: Biblioteca Nacional de España.

Tras la caída del Imperio Romano, se produjo una recesión en la proliferación de las fuentes documentales que pudiesen hacer alusión al Macizo de las Ubiñas o a espacios y poblaciones vinculadas con estas montañas, lo que ha generado un vacío de información que afecta a todo el Medioevo. No obstante, han llegado hasta nuestros días algunos testimonios, así como restos documentales y arqueológicos que permiten reconstruir las actividades y sucesos que tuvieron lugar en este espacio, además de algún evento excepcional y anécdotas históricas.

Respecto a las vías de comunicación, se tiene constancia de que el principal paso de montaña entre Asturias y León transcurrió hasta finales del siglo XVIII por El Puertu Ventana, cuando Jovellanos propuso como itinerario principal de acceso hacia la meseta el paso de El Puertu Payares. Fue a través de El Puertu Ventana, por el que se conoce actualmente como Camín Real de las Reliquias, el cual desciende por Trobaniellu hasta el pueblo de Bueida, en tierras quirosanas, por donde parecen haberse trasladado las reliquias del Arca Santa, el Santo Sudario y la Vera Cruz desde Toledo hasta su actual emplazamiento en la Cámara Santa de la Catedral de San Salvador de Uviéu, tesoros que fueron previamente custodiados en un santuario del Monsacro (ÁLVAREZ MARTÍNEZ, 2005; BENNETT, 2012; PEREIRA MIRA, 2012). El traslado aparece documentado en el Libro de los Testamentos, escrito en la tercera década del siglo XII (ÁLVAREZ MARTÍNEZ, 2005). Actualmente este camino está incluido dentro de la red de senderismo del Principado de Asturias como "G.R. 207"”.

\footnotetext{
${ }^{6}$ Floro, II, 33, 49, en Menéndez (1979).

${ }^{7}$ Orosio, VI, 21, 5, en Menéndez (1979).

${ }^{8}$ Orosio, VI, 21, 5, en Menéndez (1979).

${ }^{9}$ http://fempa.net/gr-207; http://www.caminrealdelamesa.es/camineria/es/camineria/puertoventana [consulta: 20 de enero de 2019]
} 
En Bueida, núcleo situado en el límite septentrional de las Ubiñas y popularmente relacionada con los templarios, recientemente se han realizado hallazgos arqueológicos, como su necrópolis medieval (HEVIA GONZÁLEZ y MONTES LÓPEZ, 2009). Este pueblo data, al menos, del año 891, como así lo atestigua el Liber Testamentorum, que cuenta con tres documentos históricomedievales, como el de Boida y su Iglesia de Santa María (891), en el que el santuario del pueblo aparece como una donación de Alfonso III a la Iglesia de Santo Adriano de Tuñón (prerrománica), documento que fue refrendado en el año 1100 por Alfonso VI, siendo la última referencia de 1385, anotación en la que se expresa que los vecinos de Bueida debían ir a misa a la vecina localidad de Ricao, al encontrarse su templo en estado ruinoso. Mientras que la localidad de Cortes vio nacer al promártir Fray Melchor García Sampedro (1821-1858), primer santo asturiano y Lḷindes, que pudo recuperar su historia a través de la narración de Canella y Secades y la transcripción de LUEJE (1958).

...El Coto de Lindes constituido por el pueblo y parroquia del mismo nombre, comprende todas las fincas de labor, praderas, monte alto y bajo, valladas, cañadas, río, arroyos, barrancos, pastos, majadas, abrevaderos, caminos y todo cuanto pertenece al pueblo de Lindes, que abraza una superficie, de N. a S., de doce kilómetros, y nueve de E, a O., que hacen un total de ciento ocho kilómetros cuadrados.

Por su parte, en la vertiente leonesa del macizo, ocupada por los dominios de Babia, los reyes del Reino de León (siglos X-XIII) acudían para distraerse y descansar de la vida de palacio y la empresa bélica contra los musulmanes, dedicándose a la práctica de la caza en sus bosques, a gozar de sus paisajes y a acomodarse entre sus hospitalarias gentes. En este sentido, los monarcas expidieron importantes documentos en estas tierras, siendo los más reseñables los de Fernando II y Alfonso IX. Además, destaca entre todos el Fuero de Rabanal del Camino, del año 1169, el cual fue otorgado por Fernando II y su mujer Urraca, y concedido, textualmente, "in Vaabia" (LUEJE, 1958; ÁLVAREZ, 2005). Así pues, este retiro de la realeza dio lugar a la expresión "estar en Babia", que se enuncia cuando alguien se encuentra distraído o ensimismado (ÁLVAREZ, 2005). No obstante, existe otra teoría acerca del origen de esta expresión, la cual puede proceder de los pastores trashumantes cuyos caminos circulaban entre las dehesas extremeñas y los pastos de alta montaña de las Ubiñas, ya que durante el invierno y en la soledad de los pastizales de la meseta, muchas veces se detenían a pensar en su lugar de origen y en los parajes de Babia, distrayéndose en ensoñaciones (ÁLVAREZ, 2005). Finalmente, este dicho aparece recogido en el Diccionario de la Lengua Castellana de 1822, siendo uno de los primeros personajes en utilizarlo Francisco de Quevedo (GARCÍA ARIAS, 1978).

En cuanto a la utilización del topónimo "Ubina", es necesario consultar el Archivo de la Casa de Piñera ${ }^{10}$ para poder constatar las primeras referencias al término, las cuales se retrotraen a un documento escrito el 20 de marzo de 1588, en el que figura "pena obiña" en un manuscrito de compraventa de bienes que otorgaba medio noveno del término de esta peña a Lope González del Campo y Valesquida Pérez. A este contrato hubo que añadir otros documentos de compraventa, así como cartas de pago y finanzas. El primero del 5 de enero de 1605, el segundo del 8 de septiembre de 1606 (donde se cita "pena ovina" y "peña oubiña") y el tercero y cuarto del 18 de diciembre de 1606, los cuales fueron ejercidos por diversos compradores y vendedores. Finalmente, en el índice del tomo donde se recogen estos documentos, aparecen en seis ocasiones los términos "Penaubina" y "Penaubiña". Pero estos no son los únicos documentos de este archivo donde se menciona dicho topónimo, que vuelve a figurar en una denuncia presentada por Diego Ludeña, en la que reclama que se respete su derecho de propiedad sobre el cierre de "Penaubiña", aunque se desconoce la fecha de su redacción. ${ }^{11}$ Asimismo, otro manuscrito del 14 de diciembre de 1795 describe un litigio sobre el cierre de "peñaobiñon", por lo que el anterior texto probablemente data de una fecha próxima a este último. ${ }^{12}$ En cualquier caso, la información relativa a las Ubiñas entre las Edades Media y Moderna es escasa y suscita dudas, al hallarse incompleta o sujeta a la interpretación de quienes trabajan con ella.

\footnotetext{
${ }^{10}$ Actualmente depositado en el Archivo Histórico de Asturias.

${ }^{11}$ C11262/46 (Archivo de la Casa de Piñera).

${ }^{12}$ C11262/44 (Archivo de la Casa de Piñera).
} 
Con la recopilación de datos y la redacción del Catastro del Marqués de la Ensenada (17501753), se pusieron de manifiesto, por primera vez, las características de cada población en el territorio de la Corona de Castilla. Sin embargo, en Asturias se tomó la decisión de compartimentar la información por concejos y no por pueblos, provocando que la compilación de datos fuese deficitaria en muchos núcleos rurales. Esto afectó a la parroquia de Tuíza, englobada en las respuestas del Conceyu de Lḷena, la cual ocupa poco más de dos páginas, así como a la parroquia de Ricao, comprendida en la descripción del Conceyu de Quirós. Mejor suerte corrió la parroquia de Lḷindes, que fue descrita individualmente al tratarse de una "Jurisdicción y Coto", por lo que se logró un mayor detalle. Finalmente, las respuestas de Turrebarriu son las más completas, y en ellas, fechadas el 28 de julio de 1752, se encuentra la primera descripción directa de las Ubiñas, aunque el nombre empleado, "peña de niebina", está distorsionado. Así pues, un fragmento de la decimosegunda pregunta dice:

...respondieron, que dicho lugar se halla situado a la falda deel Puerto de bentana, y della peña de niebina que es la mas alta de toda esta montaña endonde las niebes son mas abundantes $y$ duraderas y hacen notable daño en las sementeras porloqe siempre en muchos pedazos de tierra nose coje ni una espiga, y la cosecha por ese motibo es mas contingente y corta que en otros lugares comarcanos donde no ofenden tanto las niebes...

Este texto revela abundancia de nieve y un clima severo, lo que, asociado a la fecha en la que fue escrito, permite relacionarlo directamente con la Pequeña Edad de Hielo, ya que actualmente la nieve en el sector meridional del macizo resiste generalmente hasta el mes de julio y tan sólo algunos neveros de pequeñas dimensiones están presentes durante el mes de agosto por encima de 2.000 metros s.n.m., quedando las tierras de labor libres de heladas y nevadas desde el mes de junio hasta septiembre (ambos incluidos) como así lo indican los datos de la estación meteorológica de Miñera de Lḷuna, próxima en distancia y similar en altitud a Turrebarriu. Esta descripción concuerda con el comentario realizado por Joseph Townsend a su paso por Babia, en 1787, cuando observó nieve estival cercana a las tierras de cultivo (TOWNSEND, 1791). En las respuestas de Tuíza, del 22 de julio de 1752, aparece "Peña ubiña" en tres ocasiones, a la cual se alude para referirse al río Güerna, al que equivoca el autor con el Caudal, del que es afluente, así como a otro río al que no se da nombre:

Parroquia de Tuiza, hay ocho molinos arineros, uno de molar sobre el río Caudal, quevaja de Peña ubiña travaja todo el año...

Mientras que, en la tercera cuestión de las respuestas del Coto y Jurisdicción de Lindes, del 22 de julio de 1752, quedan reflejados por primera vez varios topónimos de lugares pertenecientes al Macizo de las Ubiñas en la descripción de los límites de la parroquia (figura 4), como se muestra a continuación:

Confronta por el O. Concejo de Lena y sitio que llaman el Cueto de Mallada Vieja. M. Concejo de Quirós sitio que dicen la Cueva de Valseco. L. otro Concejo y río al Cuchillar de Rueda, desde donde corta por la Loma que llaman de las tennas al N. por el que confronta con otro Concejo de Quirós, y desde aquí sigue al sitio que dicen Lende la Gallina y vega de cupinas, en donde cierra el óvalo su figura la del margen.

Finalmente, en las respuestas que incluyen a la parroquia de Ricao, con fecha del 6 de agosto de 1752, aparece una descripción similar a la anterior en la que se emplean varios de los topónimos ya citados. 
FIGURA 4

Porción de las respuestas de la Jurisdicción y Coto de Lindes del Catastro del Marqués de la Ensenada (22 de julio de 1752)

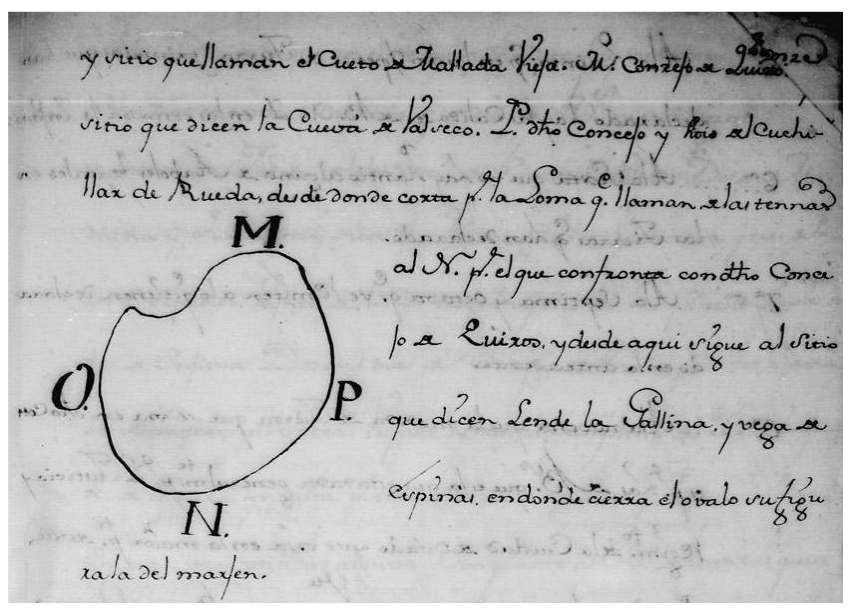

Fuente: Archivos Estatales.

Por su parte, el Diccionario Geográfico Estadístico de España y Portugal de Sebastián de Miñano (1826-1829), resultó ser la obra geográfica española más importante hasta la fecha de su edición, y aportó también nuevas referencias sobre estas montañas. En el IX volumen (1828, página 15) aparece la población de "Torre de Barrio", en la que se hace mención a las Ubiñas como "parroquia situada al pie de una gran peña". Mientras que en el V volumen (1826, página 226) se describe la población de "Lindes", detallando su entorno y sus límites de manera similar a como se hace en el Catastro del Marqués de la Ensenada, como se muestra a continuación:

Situado en el lado occidental del río y a la falda de la peña de Rueda. Linda por E. con el concejo de Lena y sitio que llaman el Cueto de Malladavieja, por S. con el concejo de Quirós y sitio que dicen la Cueva de Valseco, por O. con dicho concejo y sitio del Cuchillar de Rueda, y por N. con el que confronta con dicho concejo de Quirós y el de Llende la Gallina y Vega de Espinas.

Por otra parte, el Diccionario Geográfico-Estadístico-Histórico de España y sus posesiones de Ultramar de Pascual Madoz, supuso una mejora respecto al de Miñano, haciendo mención también a las Ubiñas en sus entradas. Así pues, en la descripción de "Murias de Paredes", contenida en el XI tomo (1848, página 757) se puede leer:

Las alturas más notables son, en la cordillera de Asturias, Peña-ubina, en la que separa las Babias de las Omañas, los riscos de Villavandin, y en la que cruza el partido de N. a S. el ya indicado Tambaron. Las crestas de las montañas de donde nacen los ríos, son calizas.

Y en el XV tomo (1849, página 64), donde se describe la población de "Torre de Barrio", aparece una referencia que denota la importancia de estas montañas para el entorno, dando además un giro toponímico hacia "Peña Ovina", lo que probablemente tenga su causa en los numerosos y cuantiosos rebaños de ovejas que pastaban en sus laderas. Asimismo, es sorprendente que en la misma obra se haga referencia a estas montañas de dos maneras, "Peña-ubina" y "Peña Ovina", lo cual es posible que se deba a que en cada población puede cambiar ligeramente la pronunciación, o que la recogida de datos fuese realizada por personas diferentes:

En su término existe la llamada Peña Ovina, de las más encumbradas del partido.

Por último, en la reseña geográfica del Anuario Estadístico de España aparecen tres referencias a las Ubiñas (COELLO, 1858, páginas 13, 17 y 24) dos veces como "Peña-Ubiña" y 
otra vez como "las peñas de Ubiña", a la que se atribuye $2.300 \mathrm{~m}$ s.n.m. ${ }^{13}$ De esta manera, se pueden encontrar escuetas menciones y descripciones como las que aquí se muestran:

Después de la alta llanura donde este nace, y que sigue á la arista Pirenaica, otro notable contrafuerte se alza al S., partiendo desde la misma cumbre en las peñas de Ubiña, el cual divide el río Bernesga del Luna.

Habiendo concluido la reseña del perímetro de la cuenca del Duero, y antes de nombrar sus diversos afluentes, vamos á dirigir una ojeada general á toda ella. Desde luego se observará que las alturas ó sierras notables, se hallan agrupadas en sus extremos, elevándose allí como inmensos mojones los picos de Peña-Trevinca, el Teleno, Peña-Ubiña, los de Europa, el de Urbion, Moncayo, Peñalara, Almanzor de Grédos y peña de Francia.

\subsection{LAS UBIÑAS EN LA CARTOGRAFÍA HISTÓRICA}

Tal y como indican GONZÁLEZ TRUEBA y SERRANO (2007), las Montañas Cantábricas han sido nombradas de diferentes maneras en la cartografía histórica a lo largo de varios siglos. En lo que respecta a la representación cartográfica de las Ubiñas, el primero en hacer referencia a ellas fue Tomás López en su Mapa del Principado de Asturias de 1777, en el que aparece la "Peña de Ubiña". No obstante, se encuentra ligeramente desviada hacia el Norte respecto a su emplazamiento real en la divisoria de aguas, y ocupa el espacio correspondiente a Pena Rueda, la cual se sitúa en el límite septentrional del macizo. El siguiente en mencionar las Ubiñas fue Martín Ferreiro en su obra Mapa de Oviedo, de 1850, donde figura la cima de "Peña Ubina". Pero fue Schulz el primero en intentar medir la altitud de la que llamó "Obiña" en su Mapa Topográfico de la Provincia de Oviedo, de 1855, a la que atribuyó 2.300 metros s.n.m. No obstante, en este mapa se vuelve a desviar hacia el Norte la peña, correspondiéndose su posición con la de El Prau. Además, incluyó otras cimas significativas como "Fariñento" con 2.200 metros s.n.m., "Requejo" con 2.100 metros s.n.m., y "Cigalia" con 2.000 metros s.n.m., y de la misma manera también los pasos de montaña de "Puerto de Ventana" a 1.380 metros s.n.m. y "Puerto de la Cubilla" a 1.430 metros s.n.m., que son el límite del macizo a poniente y levante. De estas altitudes se aprecia que todas, a excepción de El Farinientu, están sensiblemente por debajo de su cota real. Pero el mayor avance cartográfico se produjo con la edición del Atlas de España y sus posesiones de ultramar, hoja del Principado de Asturias, de COELLO (1870) (figura 5), en el cual aparece "Peña Ubiña Grande" en el lugar que correspondería estar a Los Fontanes, a la que se atribuye una altitud de 8.068 pies castellanos (2.386 metros), y "Peña Ubiña Chica". Además, se recogen otros topónimos que se plasman por primera vez en la cartografía, siendo el mapa que recopila con mayor minuciosidad los detalles de las Ubiñas hasta la fecha, el cual se tardó 81 años en superar, con la edición del primer mapa topográfico del Instituto Geográfico Nacional (IGN) en el que se incluyó al macizo.

\footnotetext{
${ }^{13}$ Altitud que probablemente fue tomada del Mapa de Asturias de Schulz (1855).
} 
FIGURA 5

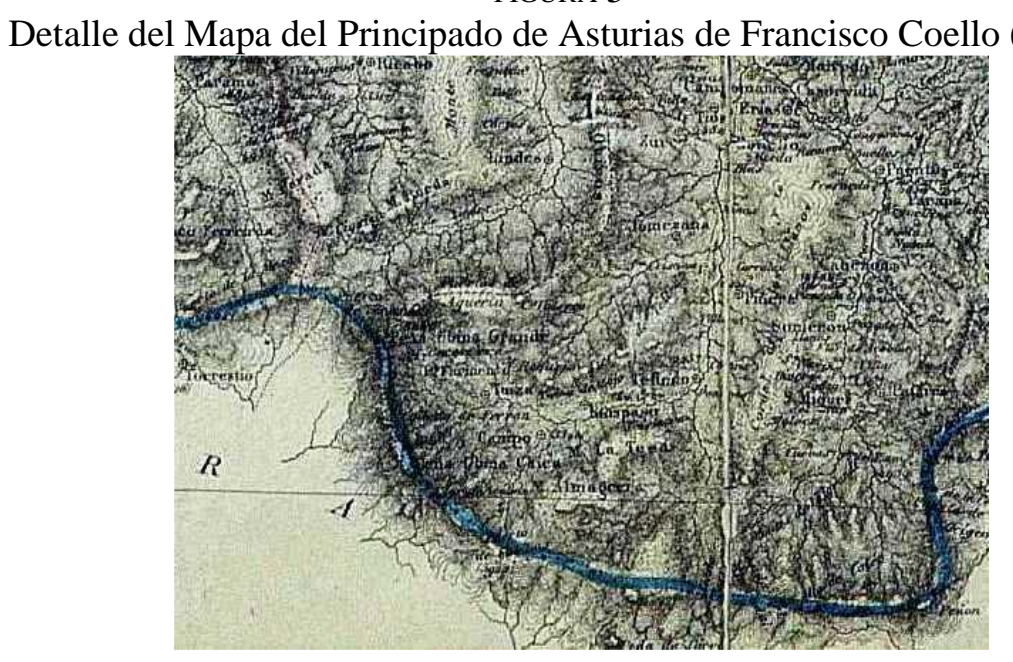

Fuente: Cartoteca del SITPA IDEAS.

Otras obras cartográficas regionales, sectoriales y nacionales en las que únicamente aparece el susodicho topónimo, son el Bosquejo Nacional Geológico de Amalio Maestre (1863), que menciona la "Peña Ubina"; el Mapa de España y Portugal de Martín Ferreiro (1867), en la que figura "Pena Ubina"; tres obras de Emilio Valverde incluidas en su Atlas Geográfico y Descriptivo de la Península Ibérica: 1) Provincia de Oviedo (1880), 2) Mapa general de la Península Ibérica, islas Baleares, Canarias y posesiones españolas (1881) y 3) Mapa del Antiguo Reino de Galicia y Principado de Asturias (1886), aludiendo en los tres a "Pa Ubiña"; finalmente cabe citar el Mapa Topográfico de la Diócesis de Oviedo, de Vallaure (1894), en el que aparece "Obina". Además, habría que añadir la cartografía de Luis de Adaro, ya que pese a haberse realizado en el siglo XX, su impronta es similar a la de los anteriores mapas y no a los posteriores. Así pues, en Bosquejo Estratigráfico de la Cuenca Central de Asturias (1914) determinó la altitud de "Peña Oviña 1" (La Grande) en 2.414 metros s.n.m., la misma cota que aparece en las últimas mediciones, y también incluyó "Peña Oviña" (La Pequena), mientras que en Corte Horizontal Estratigráfico de la Cuenca Carbonífera Central de Asturias (1915) consta "Peña Oviña", con 2.414 metros s.n.m.

Durante la primera mitad del siglo XX apenas se hicieron aportaciones a la cartografía local, siendo el Mapa Militar Itinerario de España (hoja 13, año 1920) uno de los pocos en los que figura "Peña Ubiña" con una altitud de 2.416,91 metros s.n.m. También se dibujaron esquemas durante la Guerra Civil Española que se utilizaron para marcar posiciones, en los cuales se observan topónimos y líneas a modo de isopletas. Hubo que esperar hasta la edición de la hoja del Mapa Topográfico Nacional (MTN) del IGN a escala 1:50.000 (77, La Plaza) en el año 1951, en la cual está representada casi la totalidad del macizo, para poder disponer de una nueva mejora cartográfica, aunque su tardía publicación, hace que sea una de las últimas hojas editadas de la serie del MTN. Esta obra supuso un avance significativo respecto a la cartografía precedente ya que, por primera vez, se pudieron observar el relieve, los accidentes geográficos, el poblamiento, etc. Sin embargo, la toponimia aparece notablemente distorsionada y, en algún caso, errada. Hay significativos ejemplos como la confusión de la cima de El Siete, que aparece donde deberían estar Los Fontanes, y la omisión de estos últimos; errores de este tipo se repiten a menudo por toda la hoja. Pero pese a todo, permitió un entendimiento mucho más profundo y detallado de las Ubiñas. No obstante, otros mapas sí que repararon y subsanaron estos errores (LUEJE, 1958; FEDERACIÓN ESPAÑOLA DE MONTAÑISMO, 1975; 1982; CONSEJO REGIONAL ASTURIAS, 1986).

El MTN del IGN a escala 1:25.000 no fue editado hasta el año 1997, por lo que, en casi cincuenta años, no hubo progresos relevantes. Sin embargo, con la nueva hoja (77-IV, Torrebarrio) se subsanaron muchos de los defectos cometidos anteriormente, con las isohipsas y 
demás detalles físicos correctamente representados. No obstante, aunque también mejoró sensiblemente, la toponimia siguió presentando deficiencias, en unos casos debido a una castellanización forzada de los nombres, como "Lago Turbio" en lugar de "Lleturbio" y en otros casos por omisión o confusión de sonidos en su transcripción, como "Alto Terreos" en lugar de "Altu Terreros" o "Comiso" en lugar de "Camiso", etc. En cualquier caso, este mapa tiene gran precisión, superando sensiblemente a todas las demás ediciones realizadas hasta la fecha. Las nuevas técnicas de dibujo, diseño y teledetección, permitirán que la edición a escala 1:5.000 del Principado de Asturias de 1997, que se reeditó en 2006, aporte gran precisión orográfica, representando muchos fenómenos físicos y mostrando minuciosidad en el dibujo de las poblaciones. No obstante, el mapa es pobre estéticamente y la toponimia empleada es deficitaria y, en muchos casos, errónea, precisando de una revisión y de una corrección exhaustivas. El MTN también se renovó, primero con la edición de su versión a escala 1:25.000 en 1997 y su corrección en 2002, y después con la versión a escala 1:50.000 en 2005, los cuales subsanaron muchos de los errores cometidos en la primera edición, como las isohipsas y parte de la toponimia. En cartografía topográfica destaca la producida por Adrados, quien editó un mapa del macizo a escala 1:25.000 en 2006, de gran detalle y minuciosidad, y bien resuelto, el cual además ha reparado en el cuidado de la toponimia, aunque persiste en el error de denominar "joyos" a los "fuexos". Asimismo, este mapa también se ha editado en tres dimensiones. Por su parte, el Centro Geográfico del Ejército (CGE) diseñó su propia cartografía topográfica a escala 1:50.000, la cual tiene buena resolución, editándose la hoja 77 en 2005.

\subsection{LAS UBIÑAS A TRAVÉS DE LAS ARTES GRÁFICAS, LAS MEMORIAS DE VIAJES Y LA EXPLORACIÓN CIENTÍFICA}

El ilustre gijonés Gaspar Melchor de Jovellanos (1744-1811) tuvo entre sus virtudes la de captar, en sus numerosos viajes, el entorno geográfico con excelente detalle. Así pues, en sus Diarios se encuentran menciones a las Ubiñas, como la realizada el miércoles 27 de junio de 1792, cuando a la altura de la localidad a la que llama "Candamuela" (Candemuela) dice:

... a la derecha la famosa peña de Ubiña, que se cree ser la más alta de España. Vese desde tierras de Segovia y desde muy adentro del mar. Los de Cudillero, que navegan por ella, la llaman la Becerra; va a dar al concejo de Lena.

Esto no sólo descubre que la montaña era bien conocida, sino que servía de guía tanto para los viajeros castellanos, como para los navegantes de Cudillero, siendo la distancia en línea recta entre esta localidad y la peña de aproximadamente 65 kilómetros, a los que habría que añadir los que se adentren en el mar. El mismo día que escribió el fragmento anterior, hizo también mención a "Ubiña" y a su carácter "caliar", es decir, labrada sobre roquedo calcáreo. Además, atribuye a la Sierra de Sobia un origen también calizo, a la vez que cita erróneamente la existencia en ella de formas volcánicas:

En la altísima peña de Sobia, que parte este concejo (Teberga) del de Quirós, hay otro lago en la misma cima y otro a la parte de Quirós, junto a Villamarcel. Por todas partes restos de volcanes. La peña de Sobia es caliar, y une con la de Ubiña, que lo es también.

En sus Diarios también encontramos descripciones del entorno, como la que figura en el Diario V (páginas 106 y 107), que hace referencia al río Güerna:

El río que nace en el puerto de la Cubilla: Las primeras aguas de este río nacen hacia el puerto de la Cubilla, que es una garganta colocada entre las altas peñas, de Ubiña a la derecha, y del Camero a la izquierda. El mayor de sus manantiales ofuentes es la de Vallado, la cual nace por la derecha, y después de haber corrido hasta la majada del lago, se sume en la tierra y renace en Tuiza la Cimera, corriendo después hasta frente de Tuiza la Fondera, y luego recibe las aguas que vienen por la izquierda de Nuestra Señora de Acevos, y esta confluencia es junto al pontón del Campo, por el cual va el camino del citado puerto entre uno y otro origen. Corren después estas aguas hasta cerca del lugar de Telledo, por bajo del cual se les unen las que vienen del puerto de la Bellota, situado a la izquierda del de la Cubilla, entre una altura de aquel nombre y la del Camero. Este origen o pozo, llamado Fuente Cabiyera, después de correr un corto trecho, 
se sume también y va más de media legua por bajo de tierra, renaciendo entre Pancurayedo, que está a la derecha, y la Cortina a la izquierda; y a esta misma mano, más abajo, está el lugar de Piñera. De alli se dirigen sus aguas a buscar el otro brazo que viene por Telledo, y se le junta más abajo de forma que los que van al puerto de Bellota, pasando por el pontón de Telledo, el brazo de la derecha, dejan a su izquierda Espinedo, quedando siempre a la izquierda del camino que sube a la Cubilla, como también de Jomezana y Zurea, que está a la derecha del mismo camino del río, y de Sotiello, que está sobre él. Aquí hay otro pontón con el nombre del lugar, y la casa del cura está a la izquierda del río y camino. Sigue después hasta Campomanes.

Sin embargo, CONCEPCIÓN (2011) apunta sobre este mismo texto que Jovellanos había encargado su descripción a "expertos" probablemente foráneos, y que no había hecho trabajo de campo. De ahí que su relato resulte impreciso, al no nombrar al río en cuestión y castellanizar topónimos (por ejemplo "Vallado" en lugar de "Vaḷao"), confundiendo la ubicación de El Puerto la Cubiella con la de El Meicín, entre otros errores. En cualquier caso, su valor para la Geografía es alto, al tratarse de la primera descripción realizada de este valle, aunque exista distorsión de los nombres y confusión en alguna ubicación.

Otro viajero español que dejó constancia de sus incursiones en las Ubiñas fue Mariano Lagasca y Segura (1776-1839), estudioso de la vegetación que llegó a ser director del Real del Jardín Botánico de Madrid. Lagasca, interesado en especies como la Cetraria islandica y el Senecio lagascanus, recolectó muestras de plantas y semillas en estas montañas durante julio y agosto de 1803 (LAINZ, 1991). Sin embargo, dejando a un lado la obra de Jovellanos y de Lagasca, apenas existen referencias de exploradores españoles en los siglos XVIII y XIX mientras que, desde finales del siglo XVIII, viajeros procedentes de distintos países recorrieron el espacio próximo a las Ubiñas, realizando descripciones a su paso. Además, se editaron algunas obras de descripción o de síntesis geográfica, realizadas por autores ingleses, franceses y alemanes, en las que se incluyó este macizo. Esto permite constatar, una vez más, el retraso que existió en nuestro país en el despertar del interés por los entornos naturales en general y los montañosos en particular, al menos en comparación con el que suscitó, tempranamente, entre los viajeros ilustrados de los países centroeuropeos. Entre los ingleses, es interesante el viaje realizado por Joseph Townsend, quien recorrió España entre 1786 y 1787, incluyendo su paso por Babia en agosto de 1787. En su ascensión por el río Lḷuna hasta las aldeas que llama "Truovana" (Truébano) y "Villasecino" (Vitsasecino), Townsend describió el paisaje, los pueblos y las costumbres de sus habitantes, así como las montañas y el medio físico:

A medida que avanzábamos las rocas se hacían más escarpadas, el esquisto desaparecía y el mármol se elevaba hasta trescientos o cuatrocientos pies, a menudo de forma perpendicular y a veces colgando sobre el fondo.

Como estábamos a 3 de agosto me sorprendió mucho ver entre estas montañas manchas de nieve, no muy lejos de las cuales se extendían campos en los que el trigo ya había madurado y se encontraba listo para recibir el golpe de la hoz. ${ }^{14}$

Este último fragmento muestra los efectos de la Pequeña Edad de Hielo, con neveros en la vertiente meridional que resisten en el mes de agosto, los cuales se encontraban próximos incluso a las tierras de cultivo. Este mismo fenómeno se vio reflejado también en el Catastro del Marqués de la Ensenada, lo que muestra unas condiciones climáticas más duras (GALLINAR et al., 2017).

También SMITH (1870; pág. 436), mencionó en su obra la "Peña Ubiña", a la que otorgó una altitud aproximada de 8.000 pies (2.438,4 metros), mientras que ORMSBY (1872; pág. 71) le atribuyó una altitud de 8.202 pies (2.500 metros), y la incluyó en una lista junto a las principales montañas de España. Por su parte, WIGRAM (1906; pág. 128) escribió a su paso por El Puertu Payares unas observaciones sobre "Peña Ubina", la cual llamó su atención por su vigorosidad y aspereza, llegando incluso a compararla con los Alpes, ya frecuentados por montañeros en aquella época:

\footnotetext{
14 Townsend (1791), traducción al castellano del texto original en inglés albergada en:

http://bocos.com/paginas_townsend/townsend_c4_madrid_asturias_descenso_a_asturias.htm
} 
Looking out over the abysmal valley to the wilderness of pike and fell on the westward, where the rigid outlines of the Peña Ubina are seldom destitute of snow. A rock-climber might break his neck very satisfactorily among these savage crags...

Resulta interesante el término que, tanto autores franceses como posteriormente ingleses, emplearon a finales del siglo XIX para referirse al ámbito en el que se enmarcan las Ubiñas, las Montañas Cantábricas, a las que se referían como "Pirineos Cantábricos". Utilizaban esta denominación al considerarlas una prolongación de los Pirineos hacia Poniente. Concretamente, el geólogo Charles Barrois denominó al Macizo de las Ubiñas como "Picos de Agüeria" en su tesis doctoral (BARROIS, 1882), para cuya realización se apoyó en la obra previa de SCHULZ (1855). La obra de Barrois incorporó también topónimos como "Puerto de Ventana", "Río Lindes" y "Riospaso". Además, se incluyó el susodicho topónimo en el Dictionnaire des noms propres, ou Encyclopédie illustrée de Biographie, de Géographie, d'Histoire et de Mythologie (VOREPIERRE Y MARIE BERTET, 1879). En esta obra se otorgan 2.301 metros s.n.m. a "Peña Ubiña", y en La grande encyclopédie: inventaire raisonné des sciences, des lettres et des arts (LAMIRAULT, 1885; 1902) se confunde "Peña Ubiña" (1.993 metros s.n.m.) con "Peña Rubia"15 (2.487 metros s.n.m.). Finalmente, los autores alemanes también incluyeron estas montañas en sus obras, aunque se limitaron a poner el nombre y la altitud. Así pues, en Das Ausland: Wochenschrift für Länder-u. Völkerkunde (ANÓNIMO, 1871) se le da una altitud de 8.000 pies a "Peña Ubiña" (2.438,4 metros), mientras que en Die Pyrenäische Halbinsel (WILLKOMM, 1884 ), se calculó una altitud de 2.500 metros s.n.m.

En cuanto a los montañeros, no se tiene conocimiento sobre quién o quiénes ascendieron por primera vez a las Ubiñas, pero la primera coronación de la cumbre documentada data del martes 7 de agosto de 1917 (figura 6). En ella, los montañeros asturianos Julio Galán, Álvaro Valvidares, Celso Gómez ${ }^{16}$ y R. Pérez Lozana, redactor de la memoria de la salida, hicieron cima:

Así alcanzamos la cresta más baja del macizo, y seguimos por una arista de caliza hasta dominar, a las doce, el punto más alto, donde nos encontramos con un mojón derruido. De León se ve toda la Babia, y hasta algo de la llanura; de Asturias, nada; toda la provincia está cubierta de nieblas, que tratan de penetrar por puertos y collados en León, a lo que se opone el viento. Nos distraemos un rato contemplando esta lucha de elementos.

La siguiente expedición documentada se realizó en 1922 a la Cueva Meḷuque. En ella, un grupo de espeleólogos leoneses y varios lugareños, encabezados por Suárez Uriarte, realizaron una incursión a la citada cavidad en la que afirmaron encontrar muchos espeleotemas y grabados rupestres, aunque de estos últimos no se ha encontrado más información. 
FIGURA 6

Fotografía de la primera ascensión documentada a Penubina (1917). Al fondo Los Fontanes y los farallones calcáreos que caen a la vertiente leonesa

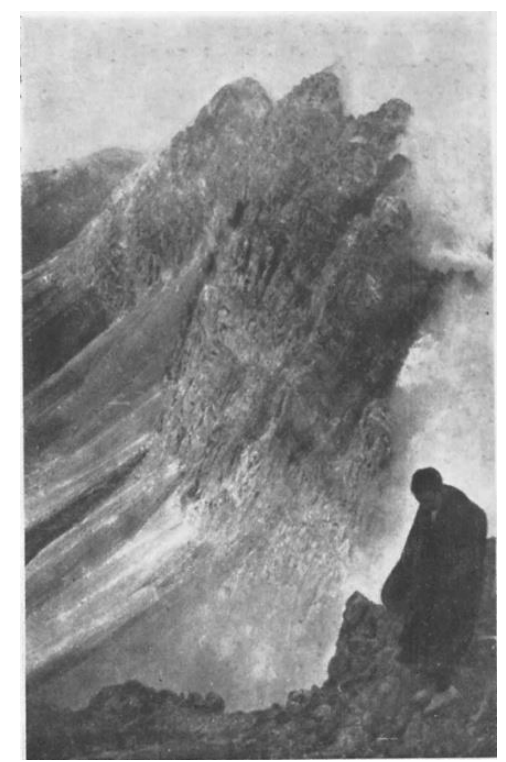

Fuente: fotografía de Celso Gómez en PÉREZ LOZANA (1917). En el pie de la imagen se lee: "Tejiendo sus cendales sutiles, la niebla asciende a velar las tres cumbres de la montaña. Peña Ubiña, soñolienta, se aislará en breve del cielo azul y de la tierra multicolora a que la retienen los muros verticales interrumpidos por los conos de deyección de los escombros".

Otro montañero que ascendió a la cima de Penubina fue el alemán Willi Rickmer Rickmers en 1925, realizando un relato (RICKMER RICKMERS, 1926) y alguna fotografía a su paso. En cuanto a la primera ascensión invernal documentada, data del 28 de febrero de 1932, en la que los montañeros leoneses Santiago Mella Alfageme, Diego Mella Alfageme y el espeleólogo alemán Felipe Frick, hicieron cima. Según sus descripciones encontraron mucha nieve en su camino. Otro visitante de cuyas salidas se tiene constancia, aunque ningún relato de una ascensión a estas cimas, es el Conde de Mieres, Manuel Loring y Martínez de Heredia, en cuya compañía acostumbraba a ir el vecino de Tuíza, Manuel Delgado, junto al cual solía recorrer estos parajes para ir de caza. Además, otros montañeros y viajeros que han dejado constancia de su presencia en estas montañas son el ingeniero, escritor y folclorista asturiano Aurelio de Llano y Roza de Ampudia (LLANO Y ROZA DE AMPUDIA, 1928). El Anuario del Club Alpino Español de 1928-1929 también reparó en el sector septentrional del macizo (Lḷaseiru y Güertos del Diablu) de la mano de Manuel G. de Amezúa. Por su parte, en 1929 Stickel exploró el entorno en busca de evidencias de glaciarismo.

No obstante, a pesar de las obras y relatos ya mencionados, hasta mediados del siglo XX las Ubiñas permanecieron al margen de las grandes expediciones decimonónicas que sí dieron testimonio de sus viajes por los Picos de Europa, y, en menor medida, por el Macizo de Fuentes Carrionas (GONZÁLEZ TRUEBA y SERRANO, 2007; PELLITERO, 2012), de modo que los valores de este espacio apenas habían sido divulgados. El montañero piloñés José Ramón Lueje (1903-1981), cuyo legado incluye 14.215 instantáneas de las cuales más de mil fueron realizadas en el Macizo de las Ubiñas entre 1942 y 1959, constituirá la excepción en este sentido. Además, Lueje publicó una obra completa dedicada a las Ubiñas (LUEJE, 1958) en cuyo contenido se encuentran una introducción histórica, la posición geográfica y los límites del macizo, una descripción de las cumbres, los puertos y los valles, así como del clima, la vegetación y la fauna, sus límites políticos, el bable de la comarca de Ubiña, las vías de comunicación existentes y doce excursiones por estas montañas. A todo esto, hay que añadir algunos dibujos e interpretaciones, un poema y doce láminas con obras de arte realizadas por Nicanor Piñole (tabla 1 y figura 7) y varias fotografías. Además, su Mapa del Macizo de Ubiña a escala 1:25.000, supuso una mejora 
sensible respecto al MTN 1:50.000 publicado siete años antes, corrigiendo muchos errores y aportando una gran cantidad de nombres que no habían aparecido previamente, posibilitando así una recuperación toponímica tan valiosa como amplia que sirvió como base para todos los trabajos posteriores. Posteriormente DELGADO (1989), incluyó este mapa en una publicación propia, añadiendo fotografías a color y nuevas excursiones y escaladas, pero manteniendo en todo momento el estilo que imprimió Lueje en su obra. No obstante, los orígenes de Lueje en el oriente de Asturias hicieron que adaptara erróneamente algunos topónimos en su cartografía, llamando joyos ${ }^{17}$ a los fuexos, término característico del oriente de Asturias para referirse a las dolinas y pozos nivocársticos, que se ha seguido empleando erróneamente en la cartografía y los trabajos hasta la actualidad, sugiriendo además que el Macizo de las 21 Ubiñas adopte el nombre que le dio Barrois (Macizo de Agüeria).

Por último, cabe destacar la labor de ciertos pintores que se interesaron por las Ubiñas a partir de principios del siglo XX (tabla 1), en el contexto de la creciente atracción que en este sentido parecían suscitar las Montañas Cantábricas y sus espacios bucólicos, rurales y naturales (LUEJE, 1958; GONZÁLEZ TRUEBA y SERRANO, 2007; MARTÍNEZ y SEVILLA, 2013), como ya había ocurrido durante el Romanticismo en otras montañas europeas como Los Alpes. Autores como Joaquín Rubio, Andrés Vidáu, Sócrates Quintana y Eugenio Tamayo, retrataron diferentes lugares y aspectos de este espacio montañoso. Pero, muy especialmente, destaca Nicanor Piñole (1878-1978), pintor postimpresionista de la Escuela de Xixón que recorrió las Ubiñas junto a José Ramón Lueje (a quien conoció en 1941) y a la agrupación de montaña Torrecerredo, representándolas en numerosas ocasiones.

\section{FIGURA 7}

Alto de Ventana por Piñole en 1958 (A); fotografía de Lueje el 11 de abril de 1947 (B); Torrebarrio por Piñole en 1958 (C y D)
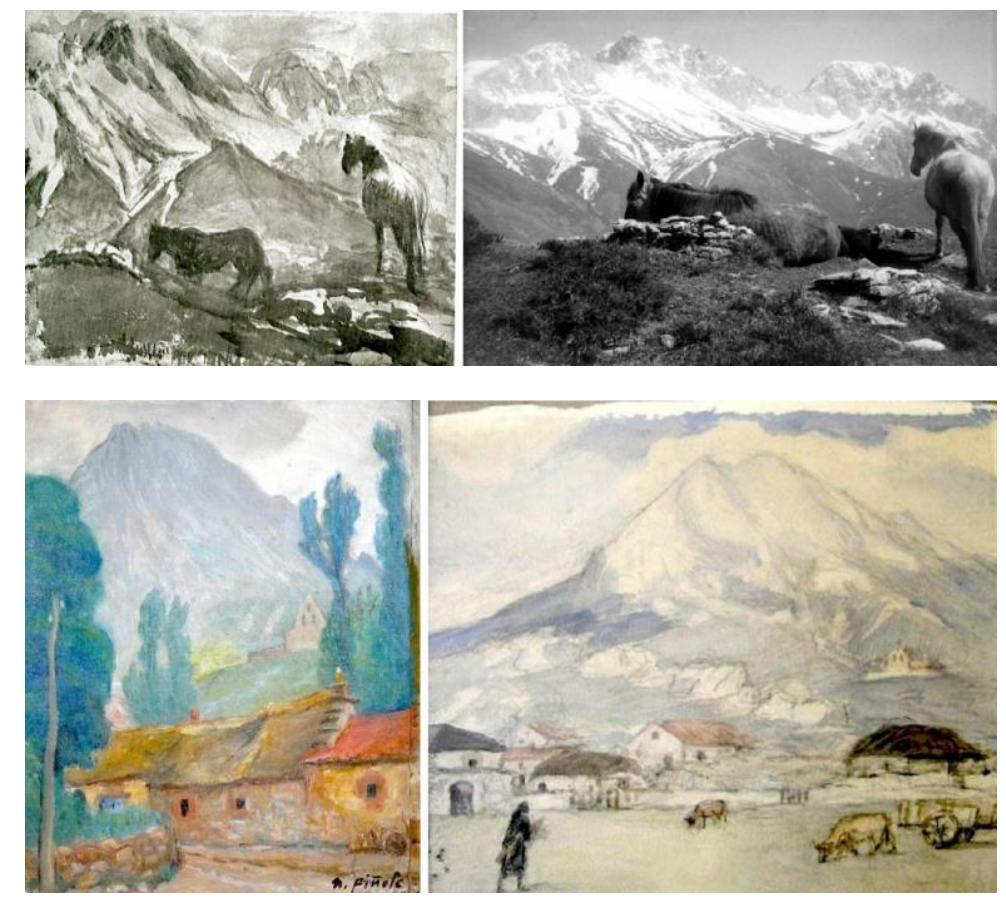

Fuente: LUEJE (1958), láminas XI y XII. Archivo fotográfico de José Ramón Lueje. 
TABLA 1

Síntesis de obras pictóricas que han reflejado el espacio de las Ubiñas

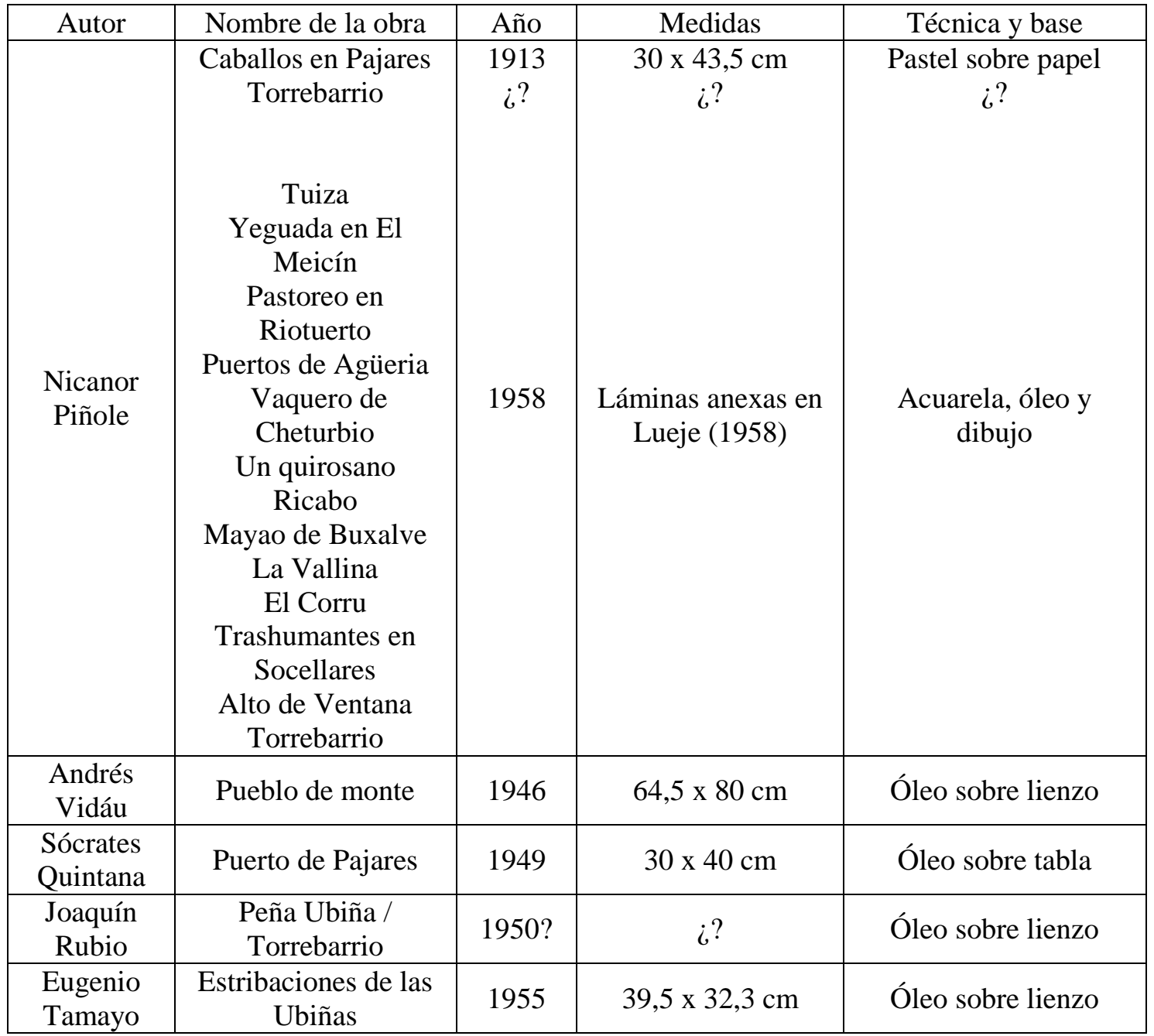

\section{LA CONFIGURACIÓN DE LAS UBIÑAS COMO ESPACIO NATURAL PROTEGIDO}

\subsection{LOS VALORES QUE HICIERON DE LAS UBIÑAS UN ESPACIO PROTEGIDO}

A finales del siglo XX, las Ubiñas fueron redescubiertas como un espacio con ingentes valores patrimoniales y paisajísticos, de índole tanto natural como cultural. En primer lugar, la variedad del sustrato geológico (SUÁREZ et al., 1990), así como la altitud alcanzada en este sector de las Montañas Cantábricas, han permitido que en este enclave montañoso la diversidad biológica sea enorme. La tercera parte del espacio de las Ubiñas está cubierta por bosques autóctonos, conteniendo 11 de las especies de flora catalogadas por parte del Principado de Asturias y constituyendo un hábitat fundamental para la conservación de especies altamente representativas del ámbito cantábrico, como el oso pardo cantábrico (Ursus arctos arctos), el urogallo cantábrico (Tetrao urogallus cantabricus) o el lobo ibérico (Canis lupus signatus) ${ }^{18}$. A estos factores, que

18 Información contenida en el informe emitido por Manuel Calvo Temprano, Director general de Biodiversidad en la Consejería de Infraestructuras, Ordenación del Territorio y Medio Ambiente del Gobierno del Principado de Asturias. Consultable en https://www.asturias.es 
de por sí confieren una gran diversidad paisajística a este territorio, debemos añadir la existencia de paisajes altamente singulares característicos de las áreas más elevadas de las Montañas Cantábricas, generados por la pasada dinámica glaciar y por el modelado, pasado y actual, derivado de la karstificación y los procesos periglaciares (GALLINAR et al., 2014).

En segundo lugar, las Ubiñas también tienen gran interés desde el punto de vista cultural. Si bien no faltan en este espacio los yacimientos arqueológicos y el arte religioso, algunos de cuyos principales elementos ya han sido reseñados en este trabajo, muchos de sus principales valores tienen origen popular. En este sentido, destaca por ejemplo la arquitectura tradicional de montaña, así como el fruto paisajístico de su dilatada historia como lugar de acogida para la trashumancia de corto y largo radio: amplios espacios de pastizal en los que se conservan construcciones (por ejemplo, las cabanas de teito) que atestiguan su importancia como enclave pastoril estival. Finalmente, en relación a su importancia como lugar de paso, las Ubiñas se ubican precisamente entre dos vías de origen romano, la de La Carisa y el Camín Real de la Mesa, las cuales constituyen de por sí un vestigio histórico de suma importancia, a lo que se añaden su valor paisajístico y su riqueza etnográfica (GALLINAR et al., 2015).

\subsection{EL PROCESO DE PATRIMONIALIZACIÓN A TRAVÉS DE LAS SUCESIVAS DECLARACIONES}

En 1991 se declaró en la vertiente leonesa el Espacio Natural Valle de San Emiliano ${ }^{19}$, mientras que en Asturias se creó en 1994 el Paisaje Protegido de Peña Ubiña, que contó con 13.281 hectáreas de superficie. ${ }^{20}$ Con el transcurso de los años, se consiguió dotar de nuevas figuras de protección y puesta en valor, como Lugar de Interés Comunitario (LIC) y Zona Especial de Protección para las Aves (ZEPA), integradas en la Red Natura 2000, así como el nombramiento de Pueblo Ejemplar de Asturias, en 1998, a la parroquia de Xomezana y el valle del Huerna. Además, se catalogaron como Lugares de Interés Geológico (LIG) el Macizo de Peña Ubiña, Los Garrafes y el Complejo Glaciar del Valle Alto Huerna - Puerto de la Cubilla. ${ }^{21}$

Con la llegada del siglo XXI entraron en vigor nuevas figuras de protección, en este caso de gran relevancia, ya que ambas vertientes fueron declaradas Parque Natural y reconocidas como Reservas de la Biosfera de la UNESCO, las cuales ocupan la extensión de los Parques Naturales. Así pues, el 29 de octubre de 2004 fue declarada la Reserva de la Biosfera de Babia, la cual contó con 38.108 hectáreas de superficie; seguidamente el 30 de mayo de 2006 se creó el Parque Natural de las Ubiñas y La Mesa ${ }^{22}$ en Asturias (figura 8), que abarca 45.162 hectáreas de extensión; y en esta misma superficie, el 11 de julio de 2012, se constituyó la Reserva de la Biosfera homónima.

\footnotetext{
${ }^{19}$ Código: ES4130035

${ }^{20}$ Código: ES1200011

${ }^{21}$ Lugares fomentados por el Instituto Geológico y Minero de España.

${ }^{22}$ Ley 5/2006, de 30 de mayo, del Parque Natural de Las Ubiñas-La Mesa. BOE núm. 188 del 8 de agosto de 2006.
} 
FIGURA 8

Mapa del Parque Natural de las Ubiñas y La Mesa

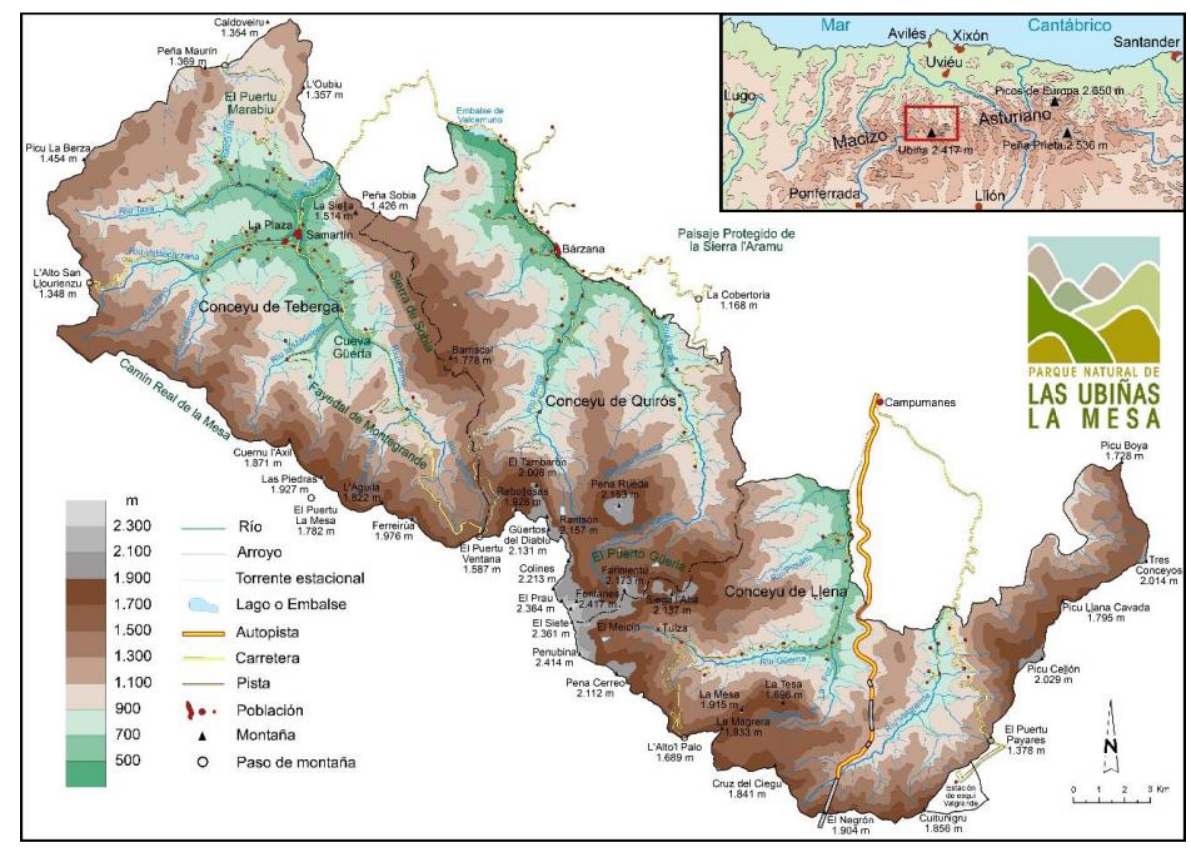

Fuente: elaboración propia.

Finalmente, el 24 de marzo de 2015 se instauró el Parque Natural de Babia y Luna ${ }^{23}$ (figura 5), con 57.757 hectáreas de superficie. Esta protección trajo consigo la limpieza de espacios degradados, siendo ejemplar el caso del entorno del nuevo refugio de El Meicín, ${ }^{24}$ donde se recogieron más de tres toneladas de basura durante una campaña de limpieza en otoño de $2009{ }^{25}$ Además, se está logrando un aumento del turismo, aunque aún dista mucho del que tienen otros espacios naturales próximos como Somiedo, Redes y especialmente los Picos de Europa (SUÁREZ-ANTUÑA et al., 2005).

Por el contrario, se está agudizando el conflicto entre el colectivo ganadero y la protección de especies como el lobo, que depreda sobre la cabaña ganadera. Además, el abandono de la ganadería extensiva se traduce en la pérdida de pastizales y, en definitiva, en una menor diversidad del paisaje. Asimismo, se plantea la necesidad de una mayor protección de algunos sectores con potencial para ser declarados monumento natural, como la crestería del macizo, y las fortificaciones de la Guerra Civil, como Bienes de Interés Cultural (BIC) (GALLINAR y DUARTE, 2015).

\section{CONCLUSIONES}

Entre las fuentes que, a lo largo de la historia, hacen referencia a las Ubiñas, destaca la información contenida en documentos regios y eclesiásticos que permiten vislumbrar la historia medieval de este territorio, marcado entonces, y también durante la Edad Moderna tal como queda registrado en las respuestas del Catastro del Marqués de la Ensenada, por su importancia como lugar de paso y espacio de pasto para los grandes rebaños de merinas procedentes de Castilla. Ya en el siglo XIX, aportaciones como las del Diccionario Geográfico Estadístico de España y

\footnotetext{
${ }^{23}$ Ley 5/2015, de 24 de marzo, de declaración del Parque Natural de "Babia y Luna» (León).

${ }^{24}$ Construido en 1967 y reconstruido con la entrada en vigor del Parque Natural de las Ubiñas y La Mesa.

${ }^{25}$ La Nueva España (30 de octubre de 2009).
} 
Portugal de Sebastián de Miñano, o como el Diccionario Geográfico-Estadístico-Histórico de España y sus posesiones de Ultramar de Pascual Madoz, hicieron mención a las Ubiñas. En cuanto a la cartografía, los datos de ubicación y altitud no empezarán a ser más precisos hasta finales del siglo XIX, siendo el Atlas de España y sus Posesiones de Ultramar de Coello (1870) el primero en registrar con cierta precisión los topónimos y cota altitudinales, el cual no será superado hasta la aparición del mapa topográfico del IGN, 81 años después. Actualmente, la cartografía es más precisa y detallada, si bien persisten ciertos errores toponímicos en la mayor parte de los casos.

Otro capítulo que aporta importante información sobre las Ubiñas es el que arrojan las memorias realizadas por exploradores nacionales y extranjeros, como Jovellanos, o como Joseph Townsend, y científicos como Barrois y Schulz. Finalmente, en la segunda década del siglo XX comienza la conquista de estos espacios por parte del montañismo, si bien hasta mediados de siglo estas montañas permanecieron al margen de las grandes exploraciones y hazañas desarrolladas en otros macizos ibéricos, como Los Picos de Europa o Los Pirineos. A pesar de esto, la labor divulgativa protagonizada por fotógrafos y montañeros como Lueje, y también por pintores que, como Piñole, inmortalizaron algunos de sus más bellos parajes, unida al progresivo interés que despertó en los aficionados a los deportes de montaña, permitieron que sus valores naturales y paisajísticos se fuesen difundiendo.

Las Ubiñas poseen una serie de valores naturales y culturales singulares, muchos de los cuales fueron apreciados desde finales del siglo XIX por quienes se acercaron a estos parajes, elaborando testimonios escritos al respecto que hoy constituyen parte fundamental del corpus documental en el que se basa este trabajo. Sin embargo, no será hasta principios de la década de 1990 cuando comiencen a darse una serie de declaraciones sucesivas que determinen su configuración como espacio cuyos valores patrimoniales deben ser protegidos. El proceso de patrimonialización culmina en la segunda década del presente siglo, cuando se declararon el Parque Natural de Babia y Luna, que había sido precedido por el Parque Natural de las Ubiñas y La Mesa, así como por las Reservas de la Biosfera homónimas.

Actualmente, estas figuras muestran su potencial para atraer cada vez a más visitantes, si bien se hace necesaria la aplicación de modelos turísticos que, por un lado, sean compatibles con el mantenimiento de los valores reseñados, los cuales son la base de su futuro desarrollo local, y, por otro, contribuyan al mismo de un modo equilibrado desde el punto de vista distributivo. Para ello, parece imprescindible lograr que las medidas de protección adoptadas tengan carácter sostenible, manteniendo los paisajes basados en la existencia de formas tradicionales de gestión agraria. La apuesta, mediante la promoción de sellos distintivos de calidad e Indicaciones Geográficas Protegidas, por los productos de alto valor natural cuya existencia deriva precisamente de esas formas de gestión tradicional (ganadería en régimen extensivo o semiextensivo), parece una de las posibles líneas de desarrollo sostenible futuro para las Ubiñas. Sin embargo, este espacio se ve afectado por las incompatibilidades que afectan a otros similares, las cuales estriban en la dificultad de combinar la protección medio ambiental y faunística con el mantenimiento de las fórmulas de manejo en extensivo que, a su vez, son básicas para el mantenimiento del paisaje. También parece importante conservar y poner en valor ciertos elementos patrimoniales altamente singulares, como el patrimonio bélico ligado a la Guerra Civil, que constituye un ejemplo paradigmático de fortificación militar defensiva ubicada en la alta montaña, muy diversa en su tipología. Por último, otro elemento cuya valoración y mantenimiento contribuirían notablemente al desarrollo sostenible de este espacio, serían, en su conjunto, las grandes vías que atraviesan las Ubiñas, huella material de su pasada historia como lugar de paso, destacando especialmente el Camín Real de la Mesa, salpicado de brañas que alojan una parte ingente y esencial del patrimonio material derivado de las actividades pastoriles en la Montaña Cantábrica. Estas son, en definitiva, algunas de las cuestiones pendientes para el desarrollo futuro de este macizo montañoso, con más de 2000 años de historia.

\section{BIBLIOGRAFÍA}

ÁLVAREZ MARTÍNEZ, M.S. (2005): "La peregrinación, el Arca de las Reliquias y su influencia artística en San Salvador de Oviedo en el siglo XII". En Lacarra Ducay, M. C. (Ed.). Los 
caminos de Santiago. Arte, historia y literatura. Institución Fernando el Católico. Zaragoza. p. 63-86.

ÁLVAREZ, G. (1949): El habla de Babia y Laciana. Consejo Superior de Investigaciones Científicas. Madrid. 337 p.

Anónimo (1871): Das Ausland: Wochenschrift für Länder-u. Völkerkunde. 42-43. Stuttgart. $1.248 \mathrm{p}$.

BARROIS, CH. (1882): Recherches sur les terrains anciens des Asturies et de la Galice. Tesis doctoral dirigida por: Fouqué, F. y Michel-Levy, A. Société Géologique du Nord. Lille. 630 p. Bennett, J. (2012): "The Sudarium of Oviedo and its Relationship with the Shroud of Turin". 1st International Scientific Congress on the Holy Shroud. Panamá. p. 1-12.

BLAS CORTINA, M.A. (1991-1992): "Nuevos testimonios metalúrgicos de la Edad del Bronce en el centro-occidente de la región cantábrica". Veleia, 8-9. p. 109-137.

BLAS CORTINA, M.A. (2011): "De la cueva al lugar fortificado: una mirada a la edad del bronce en el territorio Astur-Cántabro". Quaderns de Prehistòria i Arqueologia de Castelló, 29. p. 105-134.

CONCEPCIÓN, X. (1992A): "Motivación toponímica. Algunos animales domésticos entre los nombres de lugar". Boletín del Real Instituto de Estudios Asturianos, 139. p. 45-68

CONCEPCIÓN, X. (1992B): Toponimia lenense (Origen de algunos nombres entorno al valle del Huerna). Boletín del Real Instituto de Estudios Asturianos. Uviéu. 390 p.

CONCEPCIÓN, X. (2001): Diccionario toponímico de la montaña asturiana. KRK. Oviedo. 825 p.

CONCEPCIÓN, X. (2011): "Paisaje verbal y paisaje geográfico de Lena, vistos por Jovellanos". Boletín Jovellanista, 11. p. 71-110.

CORNEJO NIETO, C. (2014): "Geografías de recepción de los imaginarios geográficos alpinos: representaciones y narrativas de Sierra Nevada (s. XIX)". Cuadernos geográficos de la Universidad de Granada, 53(1), p. 5-35.

CORNEJO NIETO, C. (2017): "La ascensión a la montaña y la rememoración de la historia: interpretaciones de Sierra Nevada en el montañismo del siglo XIX". Documents d'anàlisi geogràfica, 63(2), p. 373-397.

DELGADO, J. (1971-1989): Ubiña alta montaña. Ed. SZ. Gijón. 214 p.

GALLINAR, D. y DUARTE, R. (2015): "Los rastros de la Guerra Civil en el paisaje del Macizo de las Ubiñas". Análisis espacial y representación geográfica: innovación y aplicación. XXIV Congreso de la AGE. Zaragoza. p. 961-967.

GALLINAR, D., GARCÍA-HERNÁNDEZ, C., RUIZ-FERNÁNDEZ, J., HERRÁN ALONSO, M. y FERNÁNDEZ, A. (2015): "Paisaje y actividad humana en el Macizo de las Ubiñas". En: Análisis espacial y representación geográfica: innovación y aplicación. XXIV Congreso de la AGE. Zaragoza. p. 969-975.

GALLINAR, D., RUIZ-FERNÁNDEZ, J. y GARCÍA-HERNÁNDEZ, C. (2017): "Los neveros del Macizo de las Ubiñas (Montañas Cantábricas) y su evolución entre 2012 y 2016". En: Ruiz-Fernández, J.; García-Hernández, C.; Oliva, M.; Rodríguez-Pérez, C. y Gallinar, D. (Eds.), Ambientes periglaciares: avances en su estudio, valoración patrimonial y riesgos asociados. Servicio de Publicaciones de la Universidad de Oviedo. Oviedo. p. 234-241.

GALliNAR, D., RUIZ-FERNÁNDEZ, J., POBLETE, M.A., FERNÁNDEZ, A., GARCÍAHERNÁNDEZ, C., BEATO, S. y MARINO, J.L. (2014): "Morfología y evolución glaciar en el sector asturiano del Macizo de las Ubiñas". En: Schnabel, S. y Gómez Gutiérrez, A. (Eds.), Avances de la geomorfología en España 2012-2014. XIII Reunión Nacional de Geomorfología, Sociedad Española de Geomorfología (SEG). Cáceres. p. 543-546.

GARCÍA ARIAS, X.LL. (1978): "Estar en Babia - Estar en las Batuecas". Boletín del Real Instituto de Estudios Asturianos, 95. p. 571-575.

GARCÍA-HERNÁNDEZ, C., RUIZ-FERNÁNDEZ, J., SÁNCHEZ-POSADA, C., PEREIRA, S., y OLIVA, M. (2018): "An extreme event between the Little Ice Age and the 20th Century: the snow avalanche cycle of 1888 in the Asturian Massif (Northern Spain)". Cuadernos de Investigación Geográfica, 44(1), p. 187-212.

GÓMEZ ORTIZ, A., OLIVA FRANGANILLO, M., SALVADOR FRANCH, F., SALVÀ CATARINEU, M., MILHEIRO SANTOS, B., PLANA CASTELlVÍ, J. A., y SERRANO 
GINÉ, D. (2012): "El paisaje reciente de Sierra Nevada, documentos escritos de época y significado geográfico de la Pequeña Edad del Hielo". Nimbus, nº 29-30, p. 305-319.

GÓMEZ ORTIZ, A., OLIVA, M., SALVADOR FRANCH, F., SALVÁ CATARINEU, M., \& PLANA CASTELLVÍ, J.A. (2018): "The geographical interest of historical documents to interpret the scientific evolution of the glacier existing in the Veleta cirque (Sierra Nevada, Spain) during the Little Ice Age". Cuadernos de investigación geográfica, 44(1), p. 267-292.

GONZÁLEZ ÁLVAREZ, D. (2016): Poblamiento y antropización de la montaña occidental cantábrica durante la Prehistoria reciente: una aproximación desde la Arqueología del paisaje. Tesis doctoral dirigida por: Gonzalo Ruiz Zapatero, Margarita Fernández Mier y Carlos Marín Suárez. Universidad Complutense de Madrid. 523 p.

GONZÁLEZ GARCÍA, N. (2005): Toponimia de la parroquia de Tuíza. Academia de la Llingua Asturiana, Toponimia 109. Llẹna. 38 p.

GONZÁlEZ TRUEBA, J.J. Y SERRANO, E. (2007): Cultura y Naturaleza en la Montaña Cantábrica. Servicio de Publicaciones de la Universidad de Cantabria. Santander. 371 p.

HEVIA GONZÁLEZ, S. Y MONTES LÓPEZ, R. (2006): "Intervención arqueológica en la necrópolis medieval de Bueida, Ricabo (Quirós)". Excavaciones arqueológicas en Asturias 2003-2006, p. 385-391.

LAMIRAULT, H. (1885-1902): La grande encyclopédie: inventaire raisonné des sciences, des lettres et des arts. Tomo 16. París. 1.213 p.

LLANO ROZA DE AMPUDIA, A. (1928): Bellezas de Asturias de Oriente a Occidente. Ed. Maxtor. Oviedo. 552 p.

LUEJE, J.R. (1958): El Macizo de Ubiña (Del Puerto de la Cubilla al de Ventana). Tipografía La Industria. Gijón. 48 p.

MARTÍNEZ DE PISÓN, E. (2004): "El paisaje de montaña. La formación de un canon natural del paisajismo moderno". En N. Ortega Cantero (ed.): Naturaleza y cultura del paisaje. Universidad Autónoma de Madrid y Fundación Duques de Soria, Madrid, pp. 15-53.

MARTÍNEZ DE PISÓN, E. (2014): “Ordesa: del valle perdido al símbolo patrimonial”, Ería, 94, p. $145-160$.

MARTÍNEZ, L.C. Y SEVILLA, J. (2013): “Al encuentro de la "geografía” en el Arte: los paisajes de la Montaña Central de Asturias”. Liño, 19. p. 81-94.

MOSCOSO-SÁNCHEZ, D. (2004): "El proceso de institucionalización del montañismo en España: una aproximación sociológica". Acciones e Investigaciones sociales, (19), p. 5-29.

NEIRA MARTÍNEZ, J. (1955): El habla de Lena. Instituto de Estudios Asturianos. Oviedo. 294 p.

OLIVA, M., GÓMEZ ORTIZ, A., PALACIOS ESTREMERA, D., SALVADOR FRANCH, F., y SALVÀ I CATARINEU, M. (2014): "El Cuaternario en el macizo de Sierra Nevada. Evolución paleoambiental y paisaje a partir de la interpretación de registros naturales y documentos de época". Scripta Nova, 18,472, p. 1-16.

ONTAÑÓN PEREDO, R. (2003): "El campaniforme en la región cantábrica: un fenómeno arqueológico en el seno de las sociedades calcolíticas del norte de la Península Ibérica". Trabajos de Prehistoria, 60, p. 81-98.

ORMSBY, J. (1872): “The Mountains of Spain”. The Alpine Journal, 5-6, p. 57-74.

ORTEGA CANTERO, N. (2009): "Paisaje e identidad. La visión de Castilla como paisaje nacional (1876-1936)", Boletín de la Asociación de Geógrafos Españoles, 51, p. 25-49.

ORTEGA CANTERO, N. (2012): "Naturaleza, cultura y símbolo: la imagen de la montaña de Peñalara en el paisajismo español moderno", Cuadernos Geográficos, 51 (2), p. 96-113.

ORTEGA CANTERO, N. (2014): "Montañismo y valoración del paisaje: la Real Sociedad Española de Alpinismo Peñalara (1913-1936)", Ería, 95, p. 253-279.

ORTEGA CANTERO, N. (2018): "Paisaje de montaña e identidad nacional: la Sierra de Guadarrama”. Ería, 38(2), p. 161-182.

PELLITERO, R. (2012): Geomorfología, paleoambiente cuaternario y geodiversidad en el Macizo de Fuentes Carrionas-Montaña Palentina. Tesis doctoral dirigida por Enrique Serrano Cañadas. Universidad de Valladolid. 1.085 p. 
PEREIRA MIRA, C.B. (2012): "La Edad Media asturiana en el año 2011: notas de bibliografía histórica. Con un aditamento al repertorio bibliográfico de los años 2009 y 2010 ”. Territorio, sociedad y poder, 7, p. 221-250.

PÉREZ, R. (1917): "Peña Ubiña y los lagos de Camayor". Peñalara, 48. p. 159-163.

RICKMER RICKMERS, W. (1926): Die Wallfahrt zum Wahren Jakob. Gebirgswanderungen in Kantabrien. Ed. Brockhause-Verlag. Leipzig. 159 p.

SCHULZ, G. (1858): Descripción geológica de la provincia de Oviedo. Imprenta y librería de Don José González. Madrid. 138 p.

SMITH (1870): "The Western Pyrenees". The Cornhill Magazine, 22-25. p. 420-436.

SUÁREZ-ANTUÑA, A., HERRÁN, M., \& RUIZ-FERNÁNDEZ, J. (2005): "La adaptación del hombre a la montaña. El paisaje de Cabrales (Picos de Europa)". Ería: revista cuatrimestral de Geografía, 68, p. 373-389.

SUÁREZ, A., HEREDIA, N, LÓPEZ, F., TOYOS, J. M., RODRÍGUEZ, L. R. y GUTIÉRREZ, G. (1990): Cartografía del mapa geológico de España 1:50.000, Hoja 102 (Los

Barrios de Luna), segunda serie, primera edición, Instituto Geológico y Minero de España.

TOWNSEND, J.A. (1791): A journey through Spain in the year 1786 and 1787. Londres. 442 p. VOREPIERRE, D. y MARIE BERTET, J.F. (1879): Dictionnaire des noms propres, ou Encyclopédie illustrée de Biographie, de Géographie, d'Histoire et de Mythologie. París. 1.390 p.

WIGRAM, E. (1906): Northern Spain. Ed. Forgotten Books. Londres. 646 p.

WILLKOMM, M. (1884): Die Pyrenäische Halbinsel. Vol. 1. Leipzig. 275 p. 